\section{Ron Judkoff (National Renewable Energy Laboratory, USA)}

\begin{abstract}
Materials advances could help to reduce the energy and environmental impacts of buildings. Globally, buildings use about $20 \%$ of primary energy and account for $20 \%$ of atmospheric emissions. Building energy consumption emanates from a variety of sources, some of which are related to the building envelope or fabric, some to the equipment in the building, and some to both. Opportunities for reducing energy use in buildings through innovative materials are therefore numerous, but there is no one system, component, or material whose improvement alone can solve the building energy problem. Many of the loads in a building are interactive, and this complicates cost/benefit analysis for new materials, components, and systems. Moreover, components and materials for buildings must meet stringent durability and cost/performance criteria to last the long service lifetimes of buildings and compete successfully in the marketplace.
\end{abstract}

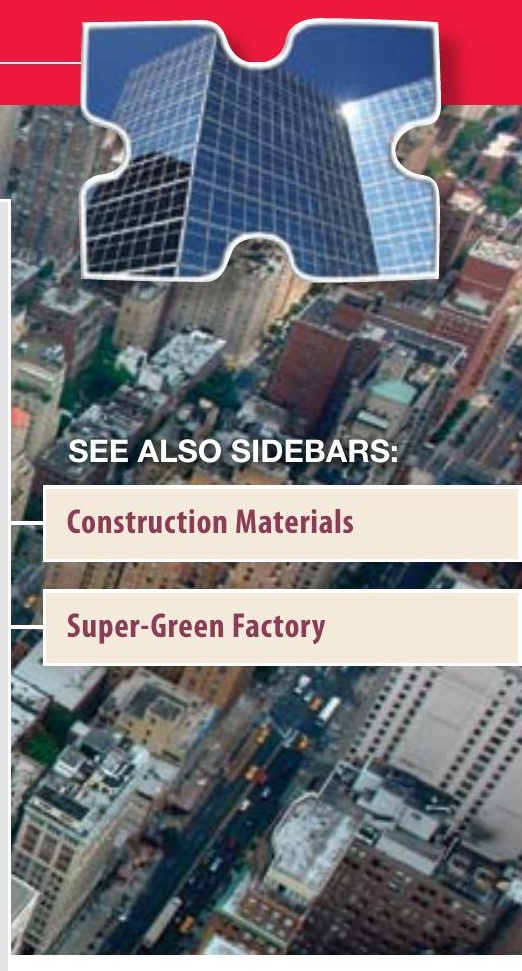

\section{Energy and Environmental Impact of Buildings}

The buildings sector accounts for about $40 \%$ of primary energy consumption, $70 \%$ of electricity use, and $40 \%$ of atmospheric emissions in developed countries. ${ }^{1}$ Globally, buildings account for about $20-30 \%$ of primary energy use and emissions. ${ }^{2}$ The disparity can be explained because many buildings in less developed countries do not provide the levels of thermal and luminous comfort common in developed nations. Also, many buildings in less developed countries have little or no access to electricity. The correlation between primary energy use and carbon emissions depends on the mix of energy sources and climate in any given country. For example, the carbon emissions from coal-fired power plants are very different from those of gas-fired plants.

Currently, total annual world primary energy consumption from human activities is about 450 quadrillion BTU (quads) (470EJ). Table I lists annual global building primary energy use projected to the year 2030.,3 World building energy use is projected to grow by about 38 quads (40EJ) by 2030 .

The current rate of total annual world anthropogenic carbon emissions is about 6,500 million metric tons of carbon equivalent per year ${ }^{5}$ (MMTCE/year). Under a business-as-usual scenario, carbon emissions will grow at least linearly with primary

\begin{tabular}{|c|c|}
\hline $\begin{array}{c}\text { Table I: Estimated Annual Rate of World Building Energy } \\
\text { Consumption. }\end{array}$ \\
\hline Year & $\begin{array}{c}\text { Energy Consumption } \\
\text { (quads/year) }\end{array}$ \\
\hline 2004 & 72.2 \\
\hline 2010 & 82.2 \\
\hline 2015 & 90.7 \\
\hline 2020 & 97.3 \\
\hline 2025 & 103.3 \\
\hline 2030 & 109.7 \\
\hline
\end{tabular}

energy consumption. A rough estimate of the current carbon emissions from the world's building stock would be about 1300 to $2200 \mathrm{MMTCE} / \mathrm{year}$.

Figure 1 shows the relative average disaggregated end uses and losses of energy in buildings (i.e., the separate contributions of individual factors to energy consumption). ${ }^{4,6}$ For example, in winter, heat leaks through walls and windows by conduction, radiation, and convection. Energy is also provided to the end uses of heating water, powering electrical devices, and heating the building, among others. These splits are most

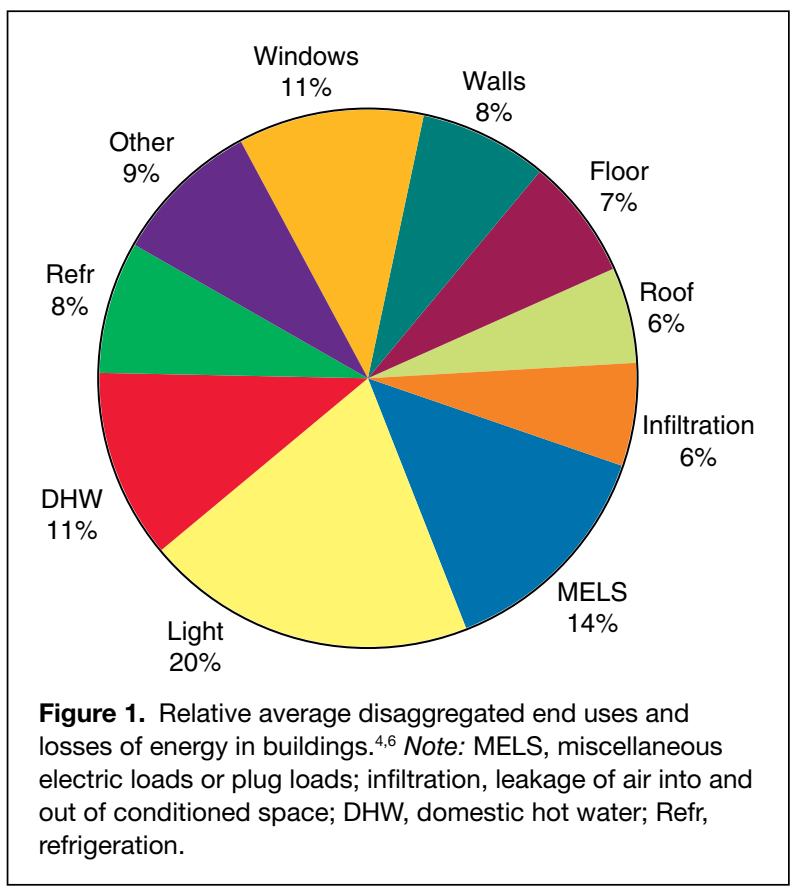


applicable in developed countries and depend on climate and building type.

From the figure, it is evident that there are no "silver bullet" solutions to the building energy problem. To radically reduce energy consumption in the building sector, all uses and losses must be addressed. Many of the loads in a building are interactive (see also the sidebar by Bonfield in this article). For example, improved insulation for walls reduces heating energy use, as does a higher efficiency furnace. The benefit-to-cost ratios of these two measures are both interdependent and dependent on the order in which they are applied to a building. In this case, whichever is applied first will appear to be better than the one that is applied second. The aggregate benefit-to-cost ratio will not be the same as the sum of the independent benefit-to-cost ratios. Smart holistic energy design attempts to take advantage of these interactions, as well as the interactions between the building and the local climate; however, the parameter space for building energy optimization is extremely large and difficult to model. Computers commonly available to architects and engineers have only recently become powerful enough to begin to address the notion of whole-building energy and cost optimization. ${ }^{7}$

One can improve building energy performance by improving the individual technologies or by optimizing the mix and interaction among all of the parameters that effect building energy use. Figure 2 shows the savings from an energyoptimized house compared to the base case of a typical house built to code. The $x$ axis shows the percent of source energy savings from the base case, and the $y$ axis shows the sum of the annual utility bill costs plus any extra annual mortgage costs for energy-saving features. At the 0 savings point ( $y$ axis), all costs are utility bills. As one moves to the right on the savings curve, the utility bill savings outweigh the additional mortgage cost for energy-efficient features, causing the curve to slope downward. The neutral cost point is the point at which the utility bill savings just balance the additional mortgage cost. In this proposed house in the Greensburg, Kansas climate, energy optimization provides nearly $60 \%$ energy savings using off-the-shelf technology at no additional cost to the building owner. The point at which the curve becomes linear is where current efficiency technology becomes more expensive than installing

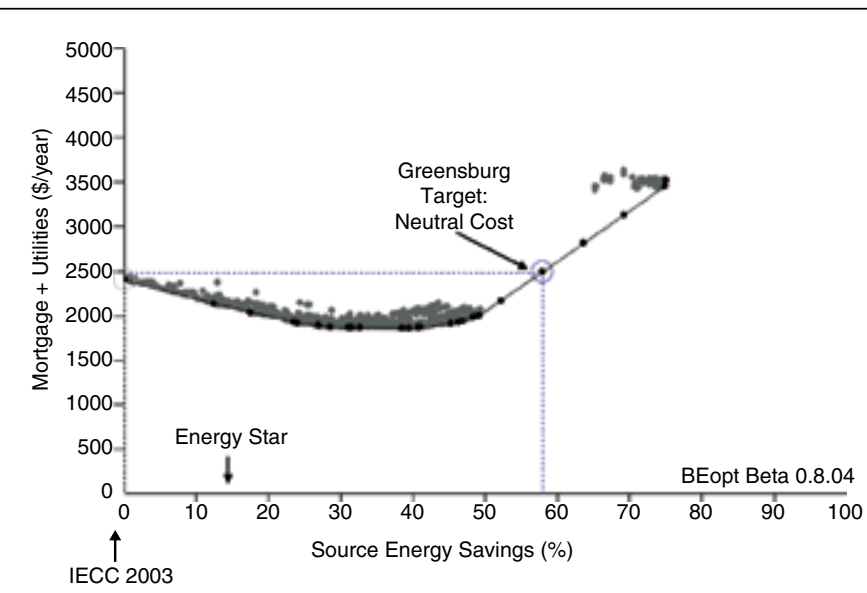

Figure 2. Savings from an energy-optimized house in Greensburg, Kansas, compared to a typical house built to code $\left(2000 \mathrm{ft}^{2}\right.$, two-story house with $16 \%$ window-to-floor area ratio and unconditioned basement). Note: IECC, International Energy Conservation Code; BEopt is the name of a building energy optimization software package under development by the National Renewable Energy Laboratory. photovoltaic (PV) panels on the roof. With the addition of a PV system, a savings of about $80 \%$ can be achieved with some extra cost to the owner. The curve stops at $80 \%$ because no more roof area is available for PV installation.

The figure shows that, to go any further toward a zeroenergy building (100\% savings on the diagram), new technology is needed. In this case, more efficient PV technology or more cost-effective efficiency measures would provide further savings. The best technology advances would move the neutral cost point farther to the right as well. To understand what is happening, think of designing a residential building in a cold sunny climate with greater window area on the south side (northern hemisphere) and correspondingly less area on the other orientations. As a result, heating load would be decreased at no additional cost and with no need for new technology. However, creating materials that allow windows to transmit heat when needed and reject heat when not needed would facilitate even more energy savings and allow greater design freedom. The challenge for materials scientists beyond creating superior materials is the difficulty in determining the potential impact a new material or component will have on the overall building energy, costs, and environmental performance over the life of the building. Despite these difficulties, the opportunities for energy savings through advanced materials are significant.

Figure 3 shows a zero-energy "Habitat for Humanity" home near Denver, Colorado, designed by the Buildings and Thermal Systems Center at the U.S. National Renewable Energy Laboratory (NREL). After a year of monitoring, the building was actually a net energy producer. Energy features of the building include: R-40 walls ( $\mathrm{R}$-value is a measure of thermal resistance and is discussed further in the next section), R-60 roof, double-glazed low-emissivity windows (high solar heat gain coefficient on the southern face), southern roof overhang for summer shading, a ventilation heat recovery system, a $4-\mathrm{kW}$ photovoltaic system on the roof, and solar water heating panels on the roof.

Figures 4a and 4b show an ultra-energy-efficient commercial building designed by NREL and the U.S. National Park Service. The building uses $65 \%$ less energy than a comparable code compliant typical building. Energy-saving features include passive downdraft evaporative cooling towers; automated natural ventilation cooling; clerestories for lighting during the day; overhangs for summer shading; photosensors and occupancy sensors to turn off electric lights when not needed; a

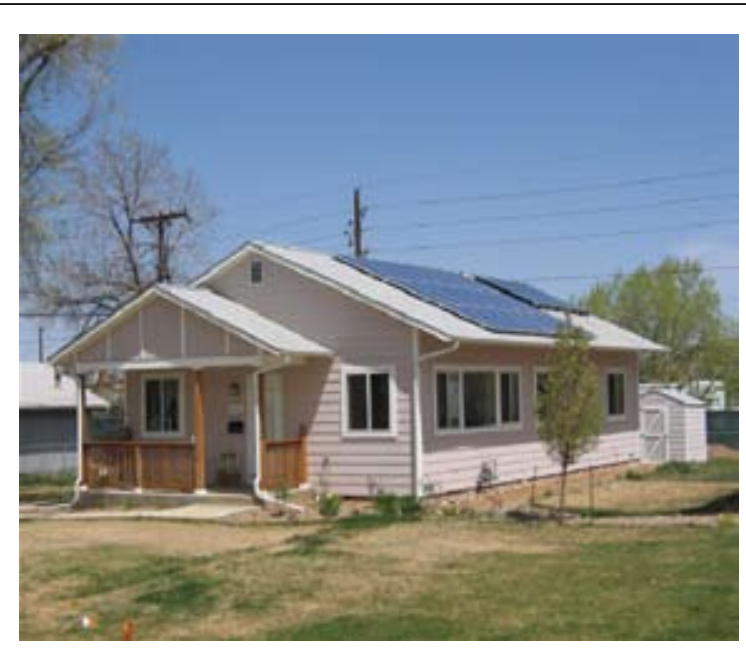

Figure 3. Zero-energy house. 

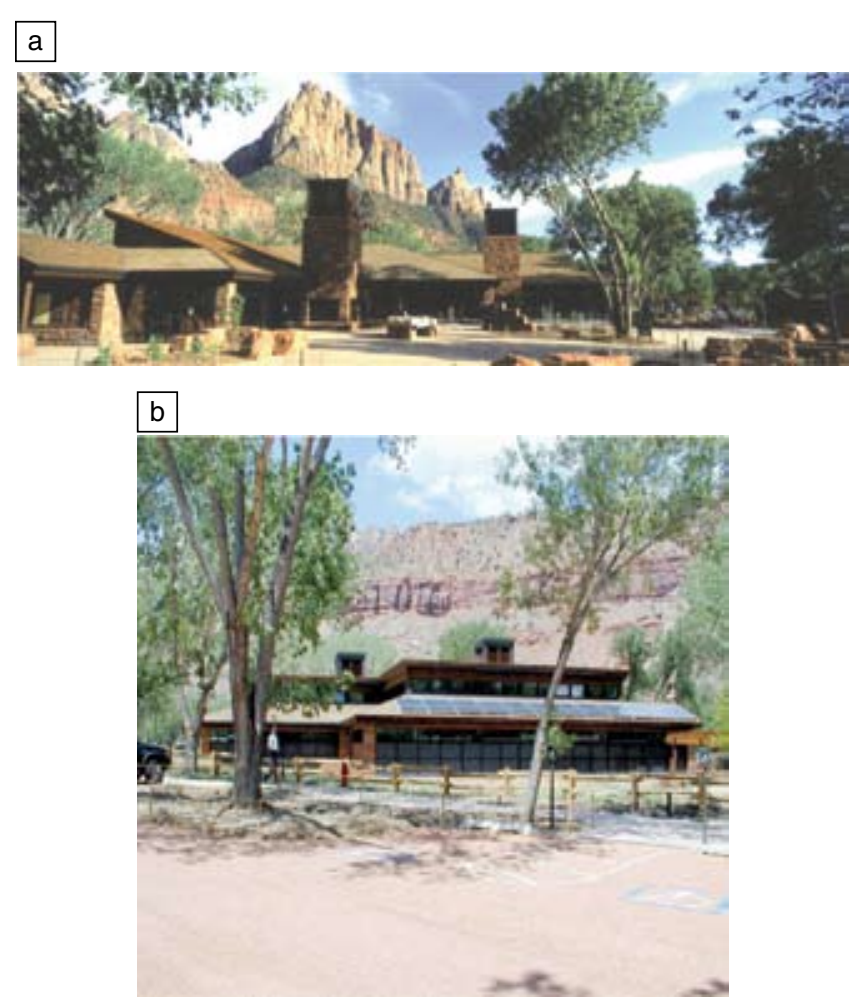

Figure 4. Zion National Park Visitor Center (Springdale, Utah): (a) North façade, (b) South façade.

thermal storage wall (trombe wall) to provide passive heating in winter; internal mass for additional heat capacitance; $7 \mathrm{~kW}$ of photovoltaics; and a computerized control system to optimally control building heating, ventilating, and air conditioning (HVAC) functions.

Another example of an energy-efficient commercial facility is described in the sidebar by Kusakabe in this article.

\section{Potential for Materials Advances Walls, Roofs, Floors (Building Envelope or Fabric)}

In the building envelope, it would be beneficial to have materials with high thermal resistance, good moisture management, and variable opaque surface properties. High thermal mass can also be beneficial when used correctly in the right climates.

Materials intended for use in the building envelope should have a high thermal resistance, or a high resistance to heat transmission in minimal thicknesses. In the building industry, thermal resistance is typically reported per unit thickness and per unit area of material in terms of R-values, which have units of hour-square foot-degrees Fahrenheit per BTU per inch $\left(\mathrm{ft}^{2}{ }^{\circ} \mathrm{F} \mathrm{h}\right) /(\mathrm{BTU}$ in.) or meter-Kelvin per watt $[(\mathrm{m} \mathrm{K}) / \mathrm{W}]$. Current thermal resistances of building insulation materials are on the order of R-3-R-7 ( $\left.\mathrm{ft}^{2}{ }^{\circ} \mathrm{F} \mathrm{h}\right) /(\mathrm{BTU}$ in.), or 18.3-44.1 (m $\mathrm{K}) / \mathrm{W}$. Materials with much higher values would be beneficial. Table II lists a few of the most common current building insulation materials. ${ }^{8}$

Researchers have developed evacuated insulation materials for buildings because of the very high R-values that are theoretically possible with such materials. This is because, in a vacuum, the heat conduction and convection mechanisms are eliminated, leaving only radiation heat transfer. Moreover, the

\begin{tabular}{|c|c|}
\hline Insulation Material & IP R-Value (SI) \\
\hline Glass fiber batts and blankets & $4(26)$ \\
\hline Chopped cellulose & $3-4(22-26)$ \\
\hline Rigid expanded perlite & $3(19)$ \\
\hline Rigid expanded extruded polystyrene & $4-5(30-35)$ \\
\hline Rigid cellular polyisocyanurate & $6(40)$ \\
\hline $\begin{array}{l}\text { Rigid cellular polyisocyanurate with gas- } \\
\text { impermeable facers }\end{array}$ & $7(50)$ \\
\hline Polyurethane foam, spray applied & $6(40)$ \\
\hline $\begin{array}{l}\text { Infrared reflective membrane }\left(\varepsilon^{\mathrm{a}}<0.5\right) \text { in } \\
\text { center of } 0.75 \text {-in. }(1.9-\mathrm{cm}) \text { cavity }^{\mathrm{b}}\end{array}$ & $3(0.57)$ \\
\hline
\end{tabular}

Note: Approximate rounded values.

${ }^{\mathrm{a}} \varepsilon$ is emissivity.

bEffective R-value for the assembly.

radiation is highly attenuated because the metallic surfaces on the inside of the component have low infrared emissivity (see Figure 5).

In practice, laboratory prototypes have been limited to R-values on the order of $15-50\left(\mathrm{ft}^{2}{ }^{\circ} \mathrm{F} \mathrm{h}\right) /(\mathrm{BTU}$ in. $)$, or 94.5 to $315(\mathrm{~m} \mathrm{~K}) / \mathrm{W}$, because of thermal short circuits from structural spacers and edge losses associated with reasonably sized modules for building applications. ${ }^{9}$ Other problems include the difficulty of maintaining a high vacuum in excess of 50 years and the danger of puncture during or after construction. Other approaches have included evacuated pouches containing low-thermal-conductivity powders. ${ }^{10}$ To date, no evacuated insulation products have substantially penetrated the building construction market.

An insulation material is a layer in a wall or roof system that must also manage moisture at both wall surfaces and within the wall. Ideally, the building envelope should present a perfect weather and water barrier. In reality, detailing is imperfect, and the interior layers of the envelope have a substantial probability of becoming wet from rain, vapor condensation, or plumbing failures at some time during their service lifetime. Materials that are impermeable to liquid water but that have passively variable vapor permeabilities would help prevent wetting and also facilitate drying after a wetting event.

Other favorable properties in terms of moisture management include the retention of a high R-value by the insulation

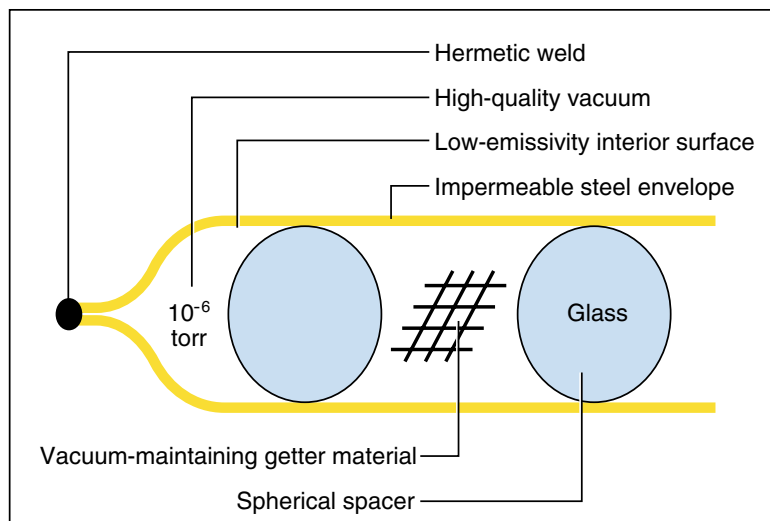

Figure 5. Schematic of compact vacuum insulation. 
layer when wet and when subsequently dried, as well as resistance to mold growth, rot, and structural damage in the presence of moisture for all materials in the wall assembly. Some proprietary materials exist that address some, but not all, of these issues. One such material is a 2-mil polyamide film that becomes more permeable to water vapor at relative humidity levels above $60 \% .^{11}$ This material is appropriate for cold and mixed climates, but it cannot be used in hot humid climates because, under conditions of outside high humidity with air conditioning inside, vapor would pass through the membrane and condense within the wall cavity wherever the surface temperature was below the dew point. Developing a material that could be used in all climates would therefore be beneficial.

Solar energy incident on the opaque exterior surfaces of a building can provide beneficial heat in winter or create additional need for cooling in summer. Exterior surface materials with variable surface optical properties could have a high solar spectrum absorptivity and low infrared emissivity in winter to help heat the building but a high solar spectrum reflectivity and high infrared emissivity in summer to help cool the building. Such surfaces would have to retain these properties for many years of weather exposure and would have to be aesthetically appropriate for the architectural context of the building. A number of light-colored and low-emissivity exterior and interior surface products exist that incorporate such materials as ceramic microspheres, microscopic metallic particles or flakes, or porcelain enamel compositions with glass and cerium oxide, but none have variable properties. ${ }^{12}$ A material with variable properties would be beneficial in all seasons and all climates. For interior surfaces, low-emissivity paint already exists, helping to reflect infrared radiation into the building in winter and resisting the emission of infrared radiation into the building in summer. The long-term durability of these exterior and interior surface properties, however, is not well known.

Materials with high volumetric heat capacitances have the ability to store a great deal of energy in a small volume. Materials such as water and masonry can store many more units of energy per unit of volume than lighter materials such as wood or plasterboard. Such heavy materials can reduce energy use and peak loads by smoothing out the diurnal load profile of the building and by retaining warmth and coolness in passive buildings designed to effectively utilize the mass. Constructing highthermal-capacitance buildings is expensive because of the need for a great deal of heavy and thermally conductive material with extensive surface area exposed to the internal spaces of the building. Modern construction tends to be lightweight, especially for internal surfaces. It would be beneficial to have inexpensive phase change materials that could be impregnated into common interior surface materials such as gypsum board. Phase change materials store and release a great deal of heat when they transform from one phase to another such as from liquid to solid and back again. These phase change materials would need to have transition temperatures in the human comfort range and be easy to contain, nontoxic, fire-retardant, and aesthetically pleasing when integrated with interior surfaces. They would also need to be nondestructive to the matrix material in which they are integrated. A number of phase change materials and containment systems have been studied for building applications by researchers such as Maria Telkes (formerly of the Massachusetts Institute of Technology), ${ }^{13}$ David Benson from NREL, Ivol Salyar and Kelly Kissock from the University of Dayton, and Jan Kozny from Oak Ridge National Laboratory. The work of these researchers and others is compiled in a reference list by D. Buddhi ${ }^{14}$ (see also the sidebar by Bonfield in this article). Examples of these materials include eutectic salts and paraffins. However, eutectic salts suffer from containment and/ or separation problems after cycling. Paraffins such as $n$-hexadecane avoid many of these problems and have good thermal properties, but they have difficulty meeting flame-spread safety codes when used at the interior wall surface. Some paraffinbased products have been developed for use as a layer buried in the wall, but this decouples the mass from the interior living space, thus reducing its effectiveness.

\section{Windows}

For windows, advances in materials science related to low-emissivity coatings, electrochromic materials, and highthermal-resistance windows would be desirable.

Current low-emissivity windows use a variety of spectrally selective and infrared reflective coatings. Such coatings are microscopically thin layers of metallic oxide usually bonded to the surfaces of glass that face the cavity in a double-glazed window. However, these windows do not change properties from summer to winter. The best window property selections for winter do not perform optimally in summer and vice versa. It would be advantageous to have selective, switchable, and/or tunable glazing materials that transmit solar energy and reflect infrared energy emanating from within the building in winter but reject solar energy and heat in summer. The glazing should also provide adequate view or visible transmittance in all modes.

Electrochromic windows are available on the market that can be darkened or lightened to reduce or increase solar transmissivity as needed. ${ }^{15}$ Advantages of electrochromics over blinds are that they involve no moving parts and are easily adapted to automated control. SAGE Electrochromics, Inc. (www.sage-ec.com), a manufacturer of electrochromic glass in the United States, describes their process as sputter coating of multiple microscopically thin layers of metal oxides through which lithium ions pass when subjected to an electric charge. Migration of the ions in one direction causes the window to darken, and migration in the other direction causes it to lighten. Although, when darkened, these glazings reduce transmissivity and heat gain compared to a clear window, they still absorb substantial amounts of solar energy in the darkened state, resulting in unwanted summer heat gains. Improved materials would be controllable for both transmissivity and reflectivity at the outer window surface, thus providing precisely the right amounts of light and heat transmission and rejection needed at any point in time.

The highest thermal resistance for windows available under current technology is R-4 $\mathrm{ft}^{2}$ of $\mathrm{h} / \mathrm{BTU}\left(0.76 \mathrm{~m}^{2} \mathrm{k} / \mathrm{W}\right.$ ) (effective resistance for assembly). Such windows are triple-glazed and have low-emissivity coatings on two surfaces and krypton gas filling the sealed spaces between the panes of glass. Such windows require very good thermal breaks and high-thermal-resistance frames to impede heat loss and gain at glazing edges and through frames. Several researchers have attempted to develop evacuated glazings to increase window thermal resistance to R10 (1.9) and above. ${ }^{16,17}$ Difficulties with such efforts included creating a good edge seal, maintaining a high vacuum in excess of 30 years, and needing to support the panes of glass with spacers while providing satisfactory visual clarity through the window.

\section{Solar Equipment}

The building industry would also benefit from advances in solar technology, particularly in terms of polymer solar domestic hot water systems and combined PV/thermal solar systems.

Current-generation solar water systems are generally fabricated from glass, copper, and aluminum and have so far been too expensive for mass-market penetration in the United States. China is the world's largest producer of glass evacu- 
ated tube collectors. Systems based on these tubes have gained traction in countries with high energy costs, limited energy availability, cheap labor, and/or favorable government policies, including Germany, Greece, and Israel. The United States is the world's largest producer of unglazed polymer water heaters for swimming pools. Such water heaters can operate at relatively low temperatures of around $70-80^{\circ} \mathrm{F}$ $\left(21-27^{\circ} \mathrm{C}\right)$, which presents no problem for ultraviolet-stabilized polymers. For use in heating domestic hot water, higher temperatures are required.

Polymer systems are favorable because they lend themselves to cost-cutting mass-production techniques (see Figures 6 and 7). A few polymer-based systems are currently marketed internationally in nonfreezing climates. In the United States, a freeze-protected system was recently introduced primarily for mild climates, and at least one other polymer-based system is under development. ${ }^{18}$ No polymer materials to date have all the properties needed for wide application in all climates. The combination of pressure, temperature, and ultraviolet (UV) exposure for solar collectors is at the limit of off-the-shelf polymer materials properties. Improvements in the properties of both glazing materials and absorbers for polymer-based solar domestic hot water systems are desirable. Ideally, one would want a glazing material that is highly transmissive in the solar spectrum, resistant to UV and weathering for more than 30 years, and dimensionally stable and structurally sound through a wide temperature range from subfreezing to a stagnation temperature of about $400^{\circ} \mathrm{F}\left(200^{\circ} \mathrm{C}\right)$. (Stagnation is a fault mode that occurs when the collector is exposed to sunlight while empty of heat-transfer fluid.) For an absorber, desired material properties include a high absorptivity in the solar spectrum, a low infrared emissivity, resistance to UV and weathering for more than 30 years, dimensional stability and structural soundness through a wide temperature range from subfreezing to a stagnation temperature of about $400^{\circ} \mathrm{F}\left(200^{\circ} \mathrm{C}\right)$ under pressures of about $200 \mathrm{psi}$, and resistance to damage from a hard freeze.

Building technology would also benefit from the development of combined PV/thermal solar systems. In typical terrestrial PV arrays, only about $10-20 \%$ of the incident solar energy is converted to electricity. The remainder of the energy is lost as heat. For building-integrated PV arrays, it would be beneficial to utilize the waste heat for purposes such as domestic hot water. This would increase the overall efficiency of the PV system, reduce building energy use, and maximize the usefulness of the limited PV-appropriate roof areas on buildings. However, all current commonly available PV materials have negative

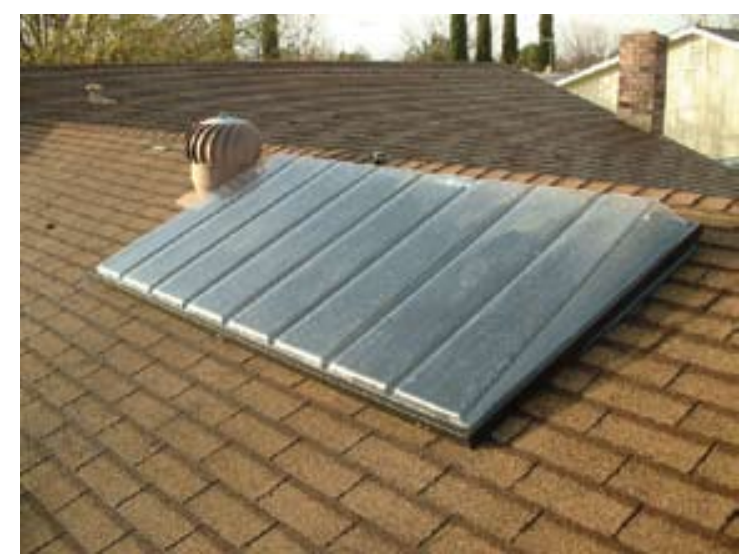

Figure 6. Prototype polymer collector. temperature coefficients, so that performance degrades as the temperature of the PV material rises. Thus, for combined PV/ thermal systems, it would be beneficial to have a PV material

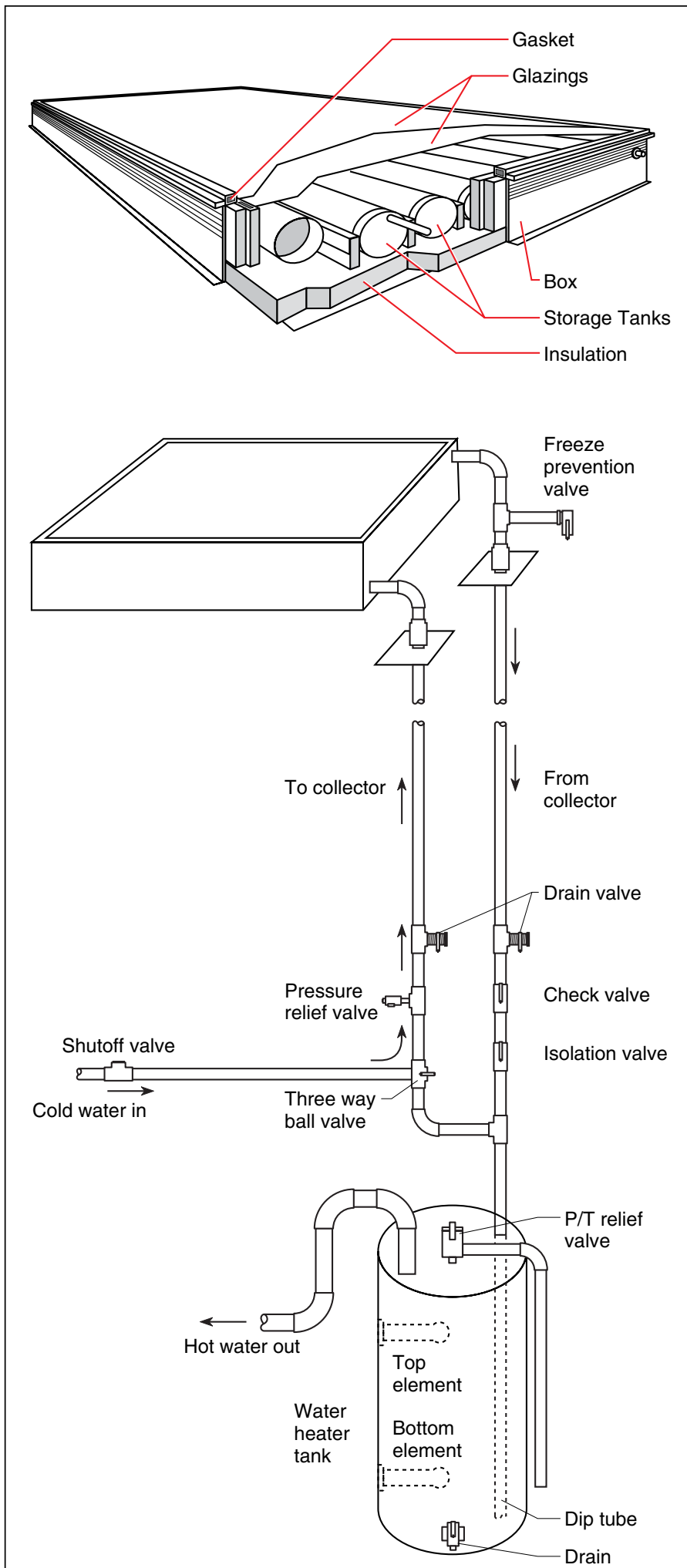

Figure 7. Integral collector-storage system. 
exhibiting little or no degradation in performance up to about $200^{\circ} \mathrm{F}\left(93^{\circ} \mathrm{C}\right)$.

\section{Conclusions}

Many opportunities are available for materials advances to reduce the energy use and atmospheric emissions associated with the building sector. The energy and cost performance of walls, roofs, windows, mechanical systems, and on-site renewable electrical and thermal systems can all be improved through advances in materials. Specifically, materials that improve the performance of thermal insulation, thermal storage, vapor retarders, weather barriers, glazings, solar thermal collectors, and photovoltaic generators could all have a profound impact on the overall energy efficiency and sustainability of buildings. Buildings have a relatively long lifecycle compared to automobiles and most manufactured products, so materials for buildings must be highly durable, nontoxic, aesthetically pleasing, and comfortable and safe for human interactions. Materials that reduce energy use in both new construction and retrofitting and refurbishment projects are needed. A challenge for building scientists and materials scientists is the difficulty of assigning a quantitative energy savings value to any given materials improvement. The elements of a building are highly interactive in their energy performance and also dependent on the surrounding climate, building type, and usage patterns in the building. Building scientists at the National Renewable Energy Laboratory have begun to develop sophisticated computer tools to address this issue, and those tools will improve as computer power increases. Because buildings are so numerous, even relatively small energy reductions on an individual-building basis can have a large impact globally.

\section{References}

1. International Energy Outlook 2007 [Report DOE/EIA-0484(2007), Energy Information Administration, U.S. Department of Energy, Washington, DC, 2007]; www.eia.doe.gov/oiaf/ieo/ (accessed January 2008).

2. Coal Facts 2006 (World Coal Institute, London, September 2006).
3. Table 8 in World Recoverable Coal Reserves as of January 1, 2003 (Report DOE/EIA-0484(2007), Energy Information Administration, U.S. Department of Energy, Washington, DC, May 2007; www.eia.doe.gov/oiaf/ieo/pdf/coal_ tables.pdf) (accessed January 2008).

4. R. Judkoff, Calculations for this paper (National Renewable Energy Laboratory, Golden, CO, August 2007).

5. Greenhouse Gases, Climate Change and Energy (Energy Information Administration, U.S. Department of Energy, Washington, DC, November 2003)

6. 2006 Building Energy Data Book (Energy Efficiency and Renewable Energy, U.S. Department of Energy, Washington, DC, September 2006).

7. C. Christensen, R. Anderson, S. Horowitz, A. Courtney, J. Spencer, BEopt ${ }^{\text {m }}$ Software for Building Energy Optimization: Features and Capabilities (Report TP-550-39929, National Renewable Energy Laboratory, Golden, C0, 2006). 8. 2005 ASHRAE Handbook-Fundamentals (ASHRAE, Atlanta, GA, 2005).

9. D.K. Benson, T.F. Potter, "Compact Vacuum Insulation," U.S. Patent 5,157,893; NREL Acc. No. 13271 (October 27, 1992).

10. B.T. Griffith, D. Arasteh, Advanced Insulations for Refrigerator/Freezers: The Potential for New Shell Designs Incorporating Polymer Barrier Constructions (Report LBNL-33376, Lawrence Berkeley Laboratory, Berkeley, CA, 1992).

11. H. Kunzel, T. Grosskinsky, Vapor Barrier for Use in the Heat Insulation of Buildings. U.S. Patent 6,808,772 B2, 2004.

12. J.A. Haines, Infrared Reflective Wall Paint. U.S. Patent 7,157,112, 2007 (and associated art).

13. M. Telkes, "Phase Change Thermal Storage Materials with Crust Forming Stabilizers," U.S. Patent 4,187,189 (1980).

14. D. Buddhi, A Selected List of References in Twentieth Century (19001999) on Phase Change Materials and Latent Heat Energy Storage Systems (Thermal Energy Storage Laboratory, School of Energy and Environmental Studies, Devi Ahilya University, Indore, India).

15. F. Pichot, S. Ferrere, R.J. Pitts, B.A. Gregg, J. Electrochem. Soc. 146 (11), 4324 (1999); NREL Report JA-590-26316.

16. D.K. Benson, C.E. Tracy, G.J. Jorgensen, Evacuated Window Glazing Research and Development: A Progress Report (Report PR-255-2578, National Renewable Energy Laboratory, Golden, C0, 1984).

17. J. Carmody, S. Selkowitz, E. Lee, D. Arasteh, T. Willmert, Window Systems for High Performance Buildings (W.W. Norton, New York, 2004).

18. J.D. Burch, NREL Report CP-550-39461, 1877 presented at ANTEC 2006 Plastics: Proceedings of the Annual Technical Conference, Charlotte, North Carolina; Brookfield, CT: Society of Plastics Engineers (SPE), 7-11 May 2006.

\title{
Environmental Performance Enters Construction Materials
}

\author{
Peter Bonfield (Building Research Establishment, UK)
}

\section{Drivers for Change}

The environmental sustainability of materials used in construction applications is driving a requirement for the quantification of performance attributes of such materials. For example, the European Union (EU) Energy Performance in Buildings Directive ${ }^{1}$ will give commercial buildings an energy rating when rented or sold. The Code for Sustainable Homes launched by the U.K. Government's Department for Communities and Local Government (CLG) in January 2007 sets out the requirement for all new homes to be carbonneutral by 2016 . In addition, homes in the United Kingdom will need to significantly reduce water consumption from today's average 160 liters (1) per person per day to less than 801 per person per day. Similarly stringent targets are required for waste, materials, and other factors. Such environmental and energy standards are complementing characteristics such as strength, stiffness, durability, impact, cost, and expected life with factors such as "environmental profile," "ecopoints" (a single unit measurement of environmental impact arising from a product throughout its lifecycle that is used in the United Kingdom), "carbon footprint" (amount of $\mathrm{CO}_{2}$ produced for the lifecycle of the item), "recycled content," and "chain of custody" (a legal term that refers to the ability to guarantee the identity and integrity of a specimen from collection through to reporting of test results).

Companies are gradually being pulled into requiring demonstrations of environmental sustainability, through regulations, customer's demands, or a general desire to make a positive contribution to protecting the planet.

This is placing new challenges on materials scientists and technologists. One of the challenges is to translate the previously rather ethereal concept of sustainability into an objective, 